University of Nebraska - Lincoln

DigitalCommons@University of Nebraska - Lincoln

Faculty Publications: Department of Entomology

January 2005

Expressed sequence tags from Diabrotica virgifera virgifera midgut identify a coleopteran cadherin and a diversity of cathepsins

\author{
Blair D. Siegfried \\ University of Nebraska-Lincoln, bsiegfried1@ufl.edu \\ N. Waterfield \\ University of Bath, Bath, UK \\ R. H. ffrench-Constant \\ University of Bath, Bath, UK
}

Follow this and additional works at: https://digitalcommons.unl.edu/entomologyfacpub

Part of the Entomology Commons

Siegfried, Blair D.; Waterfield, N.; and ffrench-Constant, R. H., "Expressed sequence tags from Diabrotica virgifera virgifera midgut identify a coleopteran cadherin and a diversity of cathepsins" (2005). Faculty Publications: Department of Entomology. 74.

https://digitalcommons.unl.edu/entomologyfacpub/74

This Article is brought to you for free and open access by the Entomology, Department of at DigitalCommons@University of Nebraska - Lincoln. It has been accepted for inclusion in Faculty Publications: Department of Entomology by an authorized administrator of DigitalCommons@University of Nebraska - Lincoln. 


\section{Expressed sequence tags from Diabrotica virgifera virgifera midgut identify a coleopteran cadherin and a diversity of} cathepsins

B. D. Siegfried*, N. Waterfield§, and R. H. ffrench-Constant§

* Department of Entomology, University of Nebraska-Lincoln, Lincoln, NE, USA

$\S$ Department of Biology and Biochemistry, University of Bath, Bath, UK

Corresponding author: Dr. Blair Siegfried, Department of Entomology, 202 Plant Industry Building, University of Nebraska-Lincoln, Lincoln, NE, USA.Tel 402 472-8714; fax 402 472-4687; Email: bsiegfried1@unl.edu

\begin{abstract}
The Western corn rootworm is the major pest of corn in the USA and has recently become the target for insect-resistant transgenic crops. Transgenic crops have switched the focus for identifying insecticide targets from the insect nervous system to the midgut. Here we describe a collection of 691 sequences from the Western corn rootworm midgut, $27 \%$ of which predict proteins with no matches in current databases. Of the remaining sequences, most predict proteins with either catalytic $(62 \%)$ or binding $(19 \%)$ functions, as expected for proteins expressed in the insect midgut. The utility of this approach for the identification of targets for novel toxins is demonstrated by analysis of the first coleopteran cadherin gene, a putative Bt receptor, and a large class of cysteine-proteases, the cathepsins.
\end{abstract}

\section{Keywords}

ESTs, Diabrotica, insect midgut, cadherin, Bt receptor, cathepsin.

\section{Introduction}

The Western corn rootworm, Diabrotica virgifera vigifera LeConte (Coleoptera: Chrysomelidae), is the most economically important pest of field corn, Zea mays (L.) in the United States (Levine \& Oloumi-Sadeghi, 1991). Recently, D. v. virgifera was also introduced into Eastern Europe and has spread rapidly, infesting more than 70,000 square miles in central Europe (Hummel, 2003). Rootworms feed on corn roots, and damaged plants are more susceptible to drought and disease, have de- creased yield, and are prone to lodging. Crop rotation and chemical control have been the primary management strategies (Levine \& Oloumi-Sadeghi, 1991), although $D$. $v$. virgifera has become increasingly difficult to control because of its sequential ability to evolve resistance to different classes of small molecule insecticides (Ball \& Weekman, 1963; Meinke et al., 1998; Zhou et al., 2002). In areas where crop rotation has been the primary management strategy, rootworms have also evolved a "behavioural" resistance involving oviposition in non-host crops (O'Neal et al., 2001; Levine et al., 2002). Those eggs deposited outside cornfields can cause significant damage to corn planted in those fields in the following year. Soil insecticides such as organophosphates and pyrethroids are still effective but pose serious environmental and human health risks, and are therefore unlikely to provide viable and long-term management options.

Current alternative management technologies include the transgenic crops that express insecticidal proteins toxic to corn rootworm larvae (Moellenbeck et al., 2001; Ellis et al., 2002). The first transgenic corn hybrids expressing $\delta$-endotoxins from Bacillus thuringiensis (Bt) were commercially available in 2003 (Environmental Protection Agency, 2003). This technology represents a significant departure from traditional crop protection chemistry, because Bt toxins act on receptors in the insect midgut rather than the insect nervous system. Although this approach offers a potentially important new direction for rootworm management, there are concerns that widespread adoption of Bt transgenic plants will rapidly lead to $\delta$-endotoxin resistance. As a consequence, receptors associated with the insect gut have become an increasingly import target for development of novel toxins including protease inhibitors (Koiwa et al., 2000), the toxin complexes (Tc's) from Photorhabdus luminescens (Liu et al., 2003) and other toxins from B. thuringiensis (Moelleneck et al., 2001; Ellis et al., 2002; Loguercio et al., 2002).

We are interested in identifying novel receptors and enzymes within the Diabrotica midgut as potential targets for Bt and alternative novel toxins (Gaines et al., 2002). 
Here we describe an expressed sequence tag (EST) strategy (Hill \& Guitierrez, 2000) for the identification of candidate receptors in the Diabrotica midgut. We discuss the relationship of these ESTs to known sequences from insects and other animals (Gaines et al., 2002) as well as their potential biological and molecular functions. The utility of this approach is illustrated by the isolation of the first coleopteran cadherin gene, encoding a putative Bt receptor (Ferré \& Van Rie, 2002; Morin et al., 2003) and also a description of the diversity of cathepsins (cysteine-proteases) expressed in the rootworm midgut, which have been identified as potential targets of protease inhibitors (Koiwa et al., 2000).

\section{Results}

\section{Diabrotica midgut ESTs}

The cDNA library from mRNA extracted from dissected D. v. virgifera larval midguts contained $2.53 \times 10^{10}$ primary clones. We sequenced 2880 clones, of which 1528 usable sequences were assembled into 190 contiguous sequences (contigs) and 501 singletons (unique sequences).The average length of readable sequences was 635 nucleotides. Each unique sequence was searched against the non-redundant GenBank database using the BLASTX algorithm. A listing of accession numbers and associated contig designations is available at http://staff.bath.ac.uk/bssrfc/EST.html .

\section{Predicted biological and molecular EST functions}

Of the 691 unique sequences, $27 \%$ (187) did not return any significant $\left(E=10^{-5}\right)$ BLASTX match (Figure $\left.1 \mathrm{~A}\right)$. Of the remaining 504 sequences, $71 \%$ had best matches to insect sequences, specifically $42 \%$ to Drosophila melanogaster and $29 \%$ to other insects (Figure 1B).Those sequences returning a significant BLASTX match were ascribed a putative biological process and molecular function (The Gene Ontology Consortium, 2001; http:// www.geneontology.org/) based on the single "best hit" match. Tables 1 and 2 summarize the molecular functions and biological processes respectively. Molecular functions correspond to activities that can be performed by individual gene products, whereas biological process are accomplished by one or more ordered assemblies of molecular functions. The distinction between a biological process and a molecular function is based on the general rule that a process must have more than one distinct step (The Gene Ontology Consortium, 2001). Strikingly, $80 \%$ of the sequences predicted proteins with either catalytic activities $(61.8 \%)$ or binding functions (18.8\%) (Figure 2A). Correspondingly, $74 \%$ of sequences were predicted to encode proteins involved in either metabolism $(64.5 \%)$ or transport $(9.1 \%)$ (Figure $2 \mathrm{~B}$ ). Several proteins known to play a biological role in the insect midgut were identified by the ESTs. For example, at least five different peritrophin-like proteins, which comprise a major component of the peritrophic membrane, were identified.

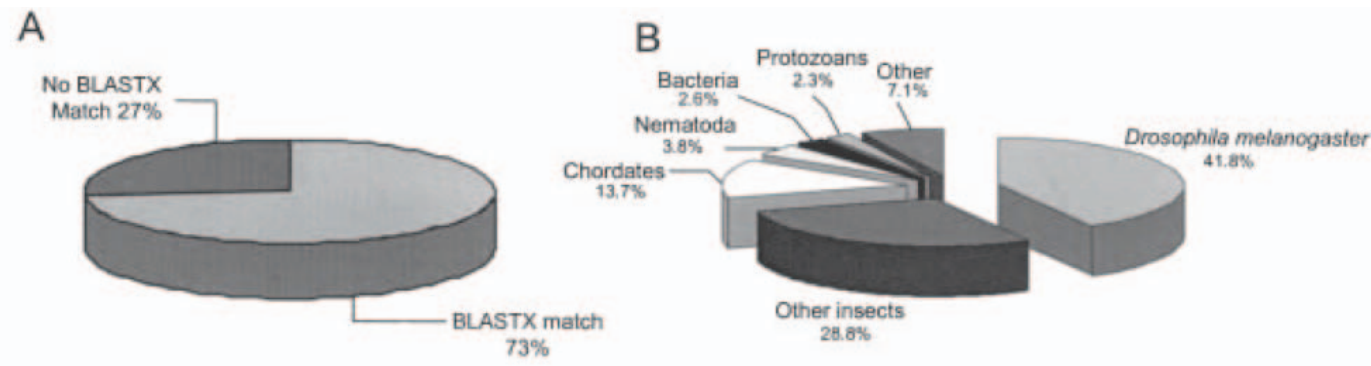

Figure 1. (A) The proportion of EST sequences with and without BLASTX matches $\left(E<10^{-5}\right)$ in GenBank. Note that $27 \%$ of the sequences did not predict the occurrence of similar proteins in current databases. (B) The percentages of sequences with matches from BLASTX classified by organism. Note that $70 \%$ of the identifiable sequences matched those found in other insects.
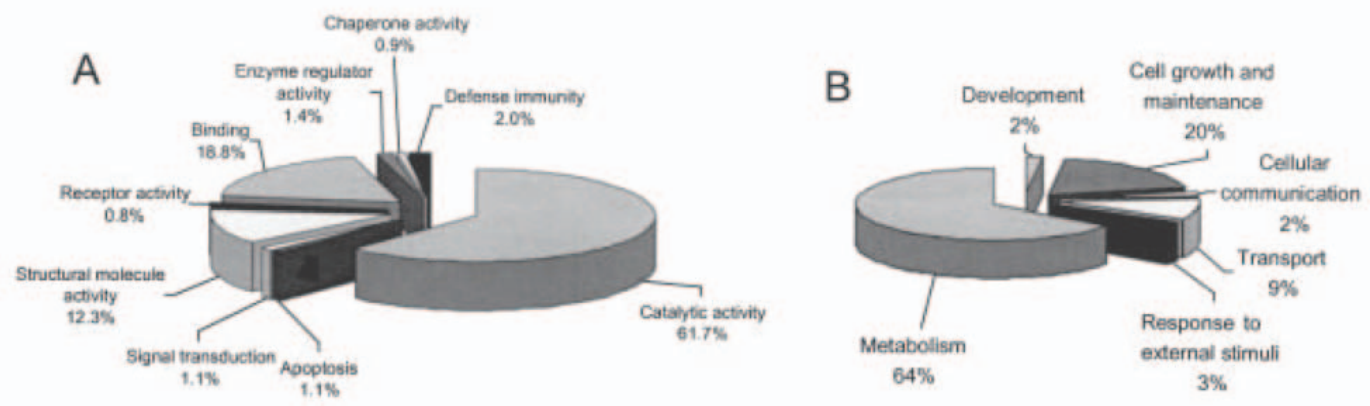

Figure 2. (A) Percentage analysis of the different biological processes ascribed to the 691 contigs by GeneOntology. Note the large percentage of predicted proteins involved in catalytic and binding activities. (B) Percentage analysis of the different molecular functions ascribed. Note the predominance of proteins involved in metabolism and transport (see text for discussion). 
Table 1. Molecular function (The Gene Ontology Consortium, 2001; http://www.geneontology.org)

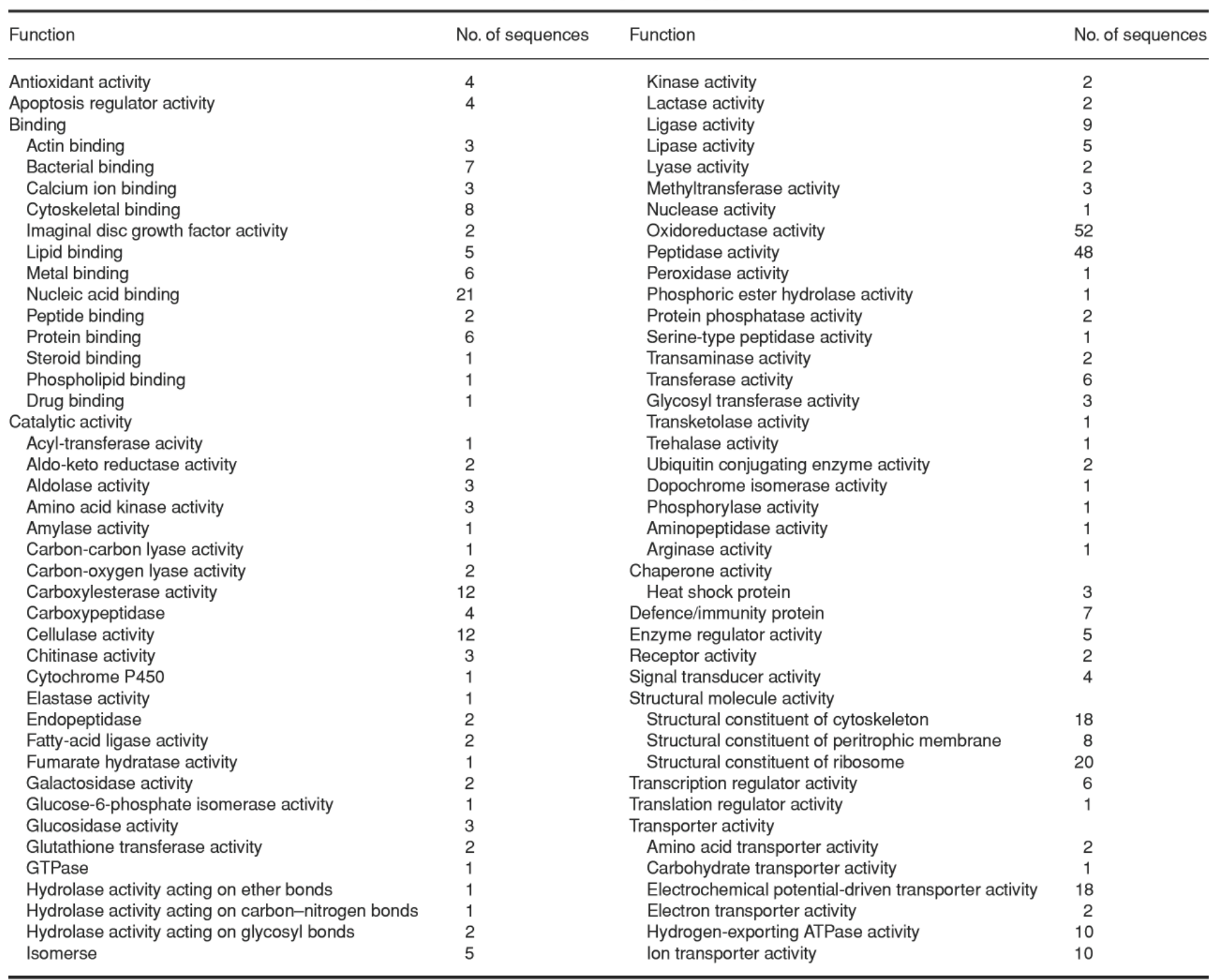

Classification is hierarchical: indented terms are children of parent terms listed above. Genes may be assigned to one or more than one term. Also note that child terms may have more than one parent term.

\section{Candidate targets for gut-specific toxins}

Two EST classes were examined in greater detail given their potential as targets for gut active toxins. These include a cadherin-like protein, which is the putative receptor for Bt toxins in Lepidoptera, and a family of cysteine proteases, the cathepsins, which have been proposed as targets for protease inhibitors. Sequence 2370 (accession number CN497270) contains a single clone predicting a protein with $29.9 \%$ identity and $48.7 \%$ similarity to a cadherin protein from the moth Lymantria dispar. We therefore sequenced this clone in its entirety. The complete clone predicts a partial cadherin protein showing regions of high identity to cadherin sequences from other insects (Figure 3). Phylogenetic analysis of the nucleotide sequences of all known insect cadherins (Figure 4) indicates that the dipteran, coleopteran and lepidoperan cadherins are all derived from a common ancestor although a greater sequence similarity between the Lepidoptera and Coleoptera is apparent.

The second class of ESTs that are candidates for gut-specific toxins predict a group of cathepsin-like proteins. The 171 individual sequences identified as cathepsin-like proteins comprised greater than $10 \%$ of the total sequences and assembled into eleven different contigs and four singletons. Visual comparison of the aligned nucleotide sequences and predictions of their consensus amino acid sequences suggest that these sequences belong to a large family of genes and are probably encoded by several independent loci. Phylogenetic analysis of the nucleotide sequences together with other $D$. $v$. virgifera cathepsin sequences available from the non-redundant GenBank database helped to clarify which proteins are likely to be encoded by allelic variants of the 
Table 2. Biological function (The Gene Ontology Consortium, 2001; http:// www.geneontology.org)

\begin{tabular}{|c|c|}
\hline Process & No. of sequences \\
\hline \multicolumn{2}{|l|}{ Cell communication } \\
\hline Cell adhesion & 1 \\
\hline Signal transduction & 6 \\
\hline \multicolumn{2}{|l|}{ Cell growth and/or maintenance } \\
\hline Carbohydrate transport & 1 \\
\hline Cell ion homeostasis & 2 \\
\hline Cell proliferation & 1 \\
\hline Cell organization and biogenesis & 30 \\
\hline Cytokinesis & 1 \\
\hline ER organization and biogenesis & 1 \\
\hline Nuclear organization and biogenesis & 1 \\
\hline Proton transport & 2 \\
\hline Receptor mediated endocytosis & 1 \\
\hline Cell homeostasis & 2 \\
\hline \multicolumn{2}{|l|}{ Development } \\
\hline Morphogenesis & 2 \\
\hline Organogenesis & 2 \\
\hline Regulation of gene expression & 4 \\
\hline Metabolism & $12^{*}$ \\
\hline Alcohol metabolism & 4 \\
\hline Aldehyde metabolism & 2 \\
\hline Amine biosysntesis & 1 \\
\hline Amino acid biosynthesis & 8 \\
\hline Amino acid metabolism & 2 \\
\hline Biogenic amine biosynthesis & 3 \\
\hline Carbohydrate metabolism & 35 \\
\hline Carboxylic acid metabolism & 1 \\
\hline Catecholamine metabolism & 3 \\
\hline Cuticle biosynthesis & 2 \\
\hline DNA metabolism & 1 \\
\hline Electron transport & 14 \\
\hline Energy pathways & 3 \\
\hline Glucose metabolism & 7 \\
\hline Glycologysis & 14 \\
\hline Glycoprotein biosynthesis & 2 \\
\hline Hormone metabolism & 1 \\
\hline Lipid metabolism & 19 \\
\hline Nucleic acid metabolism & 5 \\
\hline Nucleotide biosynthesis & 1 \\
\hline Oxidative phosphorylation & 1 \\
\hline Phosphate metabolism & 6 \\
\hline Phospholipid metabolism & 1 \\
\hline Protein biosynthesis & 28 \\
\hline Protein folding & 4 \\
\hline Protein metabolism & 62 \\
\hline Regulation of transcription & 3 \\
\hline RNA metabolism & 6 \\
\hline Serotonin biosynthesis & 2 \\
\hline Steroid biosynthesis & 1 \\
\hline Formaldehyde metabolism & 1 \\
\hline Pyruvate metabolism & 1 \\
\hline Physiological process & $17^{*}$ \\
\hline Chitin catabolism & 2 \\
\hline Immune response & 10 \\
\hline Response to external stimulus & 8 \\
\hline Response to stress & 2 \\
\hline Transcription & 3 \\
\hline Transport & $15^{*}$ \\
\hline Amino acid transport & 1 \\
\hline ATP/ADP exchange & 5 \\
\hline Lysosomal transport & 1 \\
\hline Proton transport & 9 \\
\hline Synaptic vesicle transport & 1 \\
\hline Nucleocytoplasmic transport & 1 \\
\hline Golgi vesicle transport & 1 \\
\hline
\end{tabular}

Classification is hierarchical: indented terms are children of parent terms listed above. Genes may be assigned to one or more than one term. Also note that child terms may have more than one parent term.

${ }^{*}$ Children of parent term could not be assigned. same gene or by different independent loci (Figure 5). The tree was clearly divided among two classes of cathepsin genes ( $L$ and $B$ ) as was reported previously by Brown et al. (2004). A number of sequences were similar to cathepsin genes previously identified from $D$. v. virgifera (Koiwa et al., 2000; Brown et al., 2004). However, a few genes identified in these previous studies (e.g. DvRs33 and DvRs30) apparently were not present in the cDNA library used in the present study, suggesting possible differences among populations in the composition of cathepsins.

\section{Discussion}

The present study highlights the utility of EST projects in identifying novel insecticide targets from candidate insect tissues. Previous insect EST projects have examined specific tissues such as the hindgut and Malpighian tubules of the cat flea, Ctenocephalides felis (Gaines et al., 2002), and gut tissue of cowpea weevil, Callosobrucus maculates (Pedra et al., 2003). All these these projects identified large numbers of ESTs (>25\%), without significant matches in current databases, suggesting that numerous proteins may be specific to the insect gut, and providing a useful starting point for identifying insecticide targets. Most of the Diabrotica ESTs returned matches to dipteran sequences, such as those from $D$. melanogaster. This probably reflects the current dominance of dipteran (fly and mosquito) sequences in GenBank, and the paucity of coleopteran (beetle) sequences, and is therefore not really indicative of any true phylogenetic relationships among the ESTs. The predicted biological functions of the Diabrotica ESTs support the dominant role of the midgut in binding $(19 \%$ of ESTS) and catalytic activity (62\%). These figures therefore stand in contrast to the dominance of ESTs involved in cell growth and communication found in collections of honey bee brain ESTs (Whitfield et al., 2002).

The Diabrotica ESTs predict a variety of proteins that are highly expressed in the midgut, such as pertitrophin, a major component of the peritrophic membrane. However, the collection also contains tags for specific proteins of lower abundance, such as the Diabrotica cadherin which is, to our knowledge, the first coleopteran cadherin to be identified. Although the predicted protein contains several regions of high identity to lepidopteran proteins (Figure 3), the overall level of amino acid identity suggests that this cadherin gene may have been hard to clone via low-stringency hybridization or the use of degenerate primers in the polymerase chain reaction. The isolation of this EST among a relatively small EST sample size therefore illustrates the utility of a tissuespecific approach. Although there is still considerable debate over the relative role of cadherins in the binding of $\mathrm{Bt} \delta$-endotoxins to the insect midgut, cloning and 


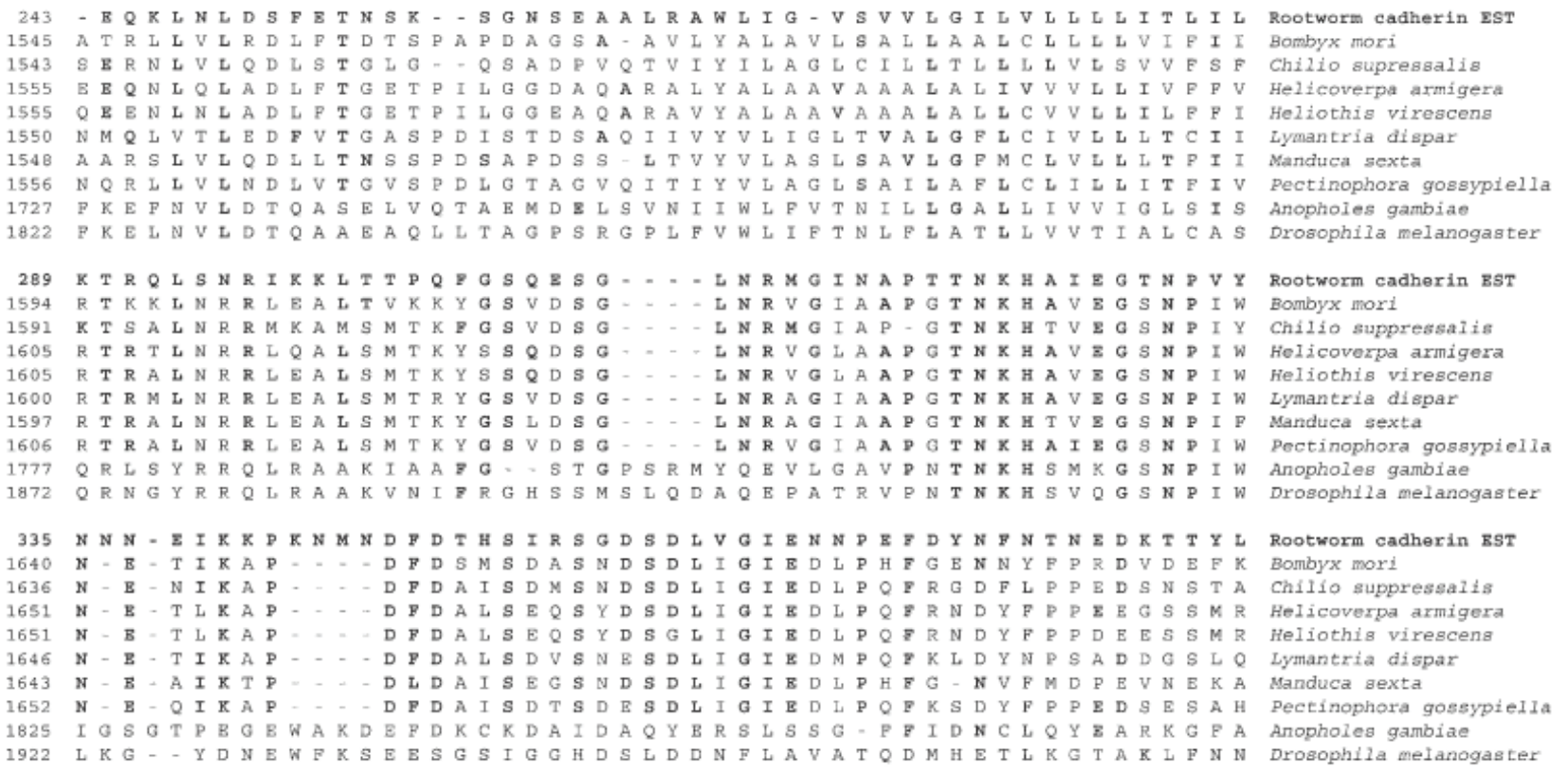

Figure 3. Amino acid alignment of known cadherin genes with $D$. v. virgifera cadherin sequence (AY769085). Amino acids shared with the $D$. $v$. virgifera sequence are highlighted in bold. Aligned sequences for cadherin genes with accession numbers are Bombyx mori (BAA99405), Manduca sexta (AAM21151), Lymantria dispar (AAL26896), Helicoverpa armigera (AAM65319), Heliothis virescens (AAK85198), Chilo supressalis (AAM75590), Pectinophora gossypiella (AAP31705), Anopholes gambiae (XM321513) and Drosophila melanogaster (AAF55082).

Figure 4. Phylogenetic tree of known cadherin sequences in relation to $D$. v. virgifera cadherin EST. See Figure 3 for accession numbers.

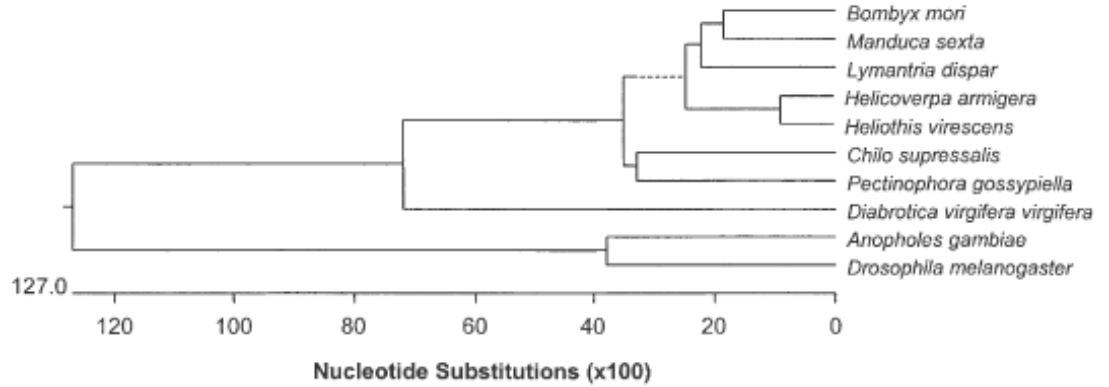

Nucleotide Substitutions (x100)

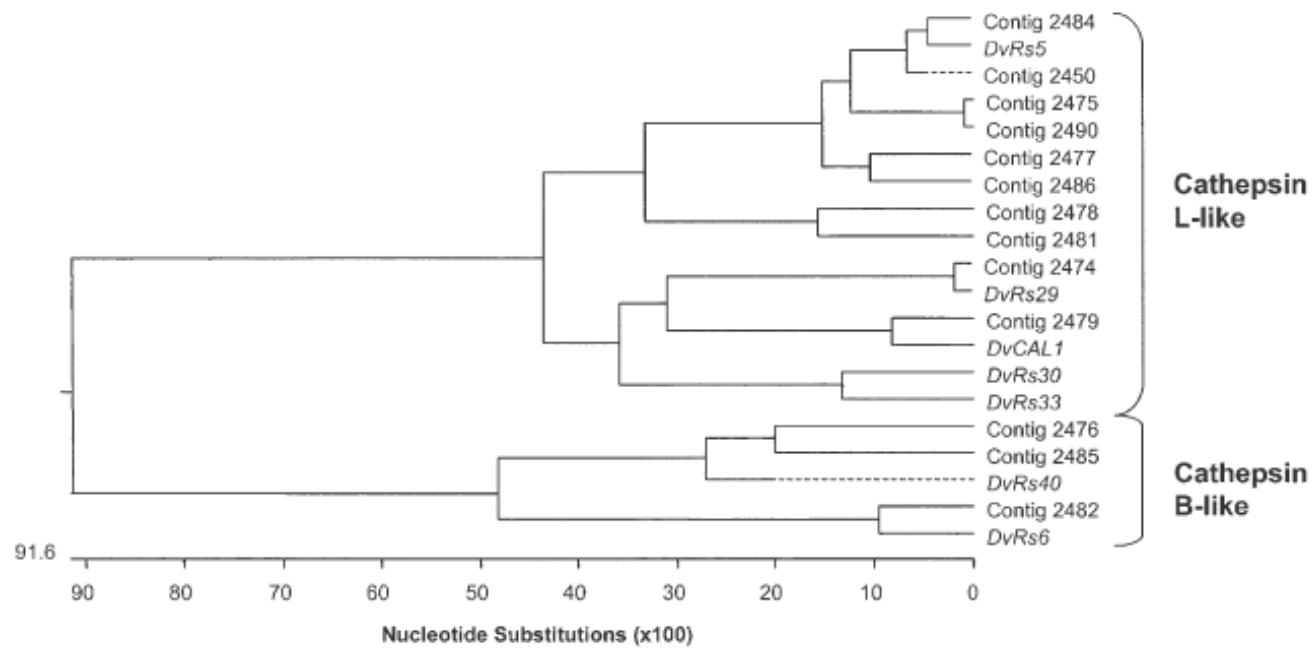

Figure 5. Phylogentic tree of cathepsin-like enzymes predicted by clones isolated from $D$. v. virgifera larval midgut cDNA library. Aligned sequences of D. v. virgifera cathepsins with accession numbers are DvRs5 (AJ583508), DvRs29 (AJ583510), DvRs30 (AJ583511), DvRs33 (AJ583512), DvRs40 (AJ583513), DvRs6 (AJ583509) and DvCAL1 (AAG17127). Accession numbers for individual EST clones associated with each contig are available at http://staff.bath.ac.uk/bssrfc/EST.html. 
functional expression of the Diabrotica cadherin gene will allow us to test its role in toxin binding directly and perhaps begin to dissect the relationship between taxonomic status and specificity of various cry toxins from Bacillus thuringiensis.

One of the largest groups of ESTs identified in the EST database was the cathepsin-like cysteine proteases. Unlike that seen in mammals and most insects, digestive proteolysis by coleopterans (including $D$. $v$. virgifera) is predominantly due to cysteine proteinase activity (Gatehouse et al., 1985; Murdock et al., 1988; Lilley et al., 1997; Koiwa et al., 2000). Examination of the EST sequences reveals a large diversity of cysteine proteases within the rootworm midgut that apparently are highly expressed given that $>10 \%$ of the clones were identified as cathepsin hits. Previously, Koiwa et al. (2000) resolved five major peptides by affinity chromatography which exhibited similar N-terminal sequences and suggested that the digestive proteolytic system of rootworms is derived from products of a multigene family. Recently, Brown et al. (2004) reported that a cDNA library representing $D$. $v$. virgifera larval gut tissue mRNA contained cysteine proteinase-encoding clones at high frequency $(15 \%)$ although only seventy clones were sequenced. Sequence analysis revealed eleven cysteine proteinases, nine of which were cathepsin L-like enzymes and another two cathepsin B-like enzymes. The present study is in agreement with these results except that the diversity of cathepsins appears to be even greater than reported by Brown et al. (2004).

In the absence of complete genome sequences for beetle pests, EST sequencing is likely to remain a useful tool in the identification of candidate proteins for novel toxins. Tissue-specific EST projects in different beetle pests, such as Tribolium, should enable us to establish what percentage of the unidentified midgut ESTs correspond to beetle-specific gut proteins. In this fashion, we should be able to ascertain not only which proteins are specific to insects as a whole but also which are specific to certain insect tissues, presenting candidate insect and tissue-specific insecticide targets.

\section{Experimental procedures}

\section{Library preparation and EST sequencing}

Midguts were dissected from approximately 800 thirdinstar western corn rootworm larvae and flash frozen in liquid nitrogen. The dissected tissue was shipped on dry ice to Invitrogen (Carlsbad, CA, USA), where a microquantity cDNA library was prepared from poly $\mathrm{A}^{+}$selected mRNA using SuperScript II RNase $\mathrm{H}^{-}$reverse transcriptase (Invitrogen Life Technologies). The total number of primary clones $\left(2.53 \times 10^{10}\right)$ in the library and their average insert size $(1.7 \mathrm{~kb})$ were estimated. Escherichia coli (strain ElectroMax DH10b ton A) colonies containing individual cDNA clones were picked into ninety-six-well deep-well microtitre plates and grown overnight in $2 \times$ Yt supplemented with ampicillin $(100 \mu \mathrm{g} / \mathrm{ml})$ antibiotic. Glycerol $(20 \% \mathrm{v} / \mathrm{v})$ was added to aliquots of these overnight cultures for the preparation of freezer stocks. DNA was prepared from the remainder of the overnight culture using a plasmid-preparing robot (MWG RoboPrep 2500), and the clones were sequenced using the SP6 sequencing primer on an $\mathrm{ABI} 3700$ capillary sequencer. As the library was directionally cloned, this primer sequenced through the $5^{\prime}$ end of the cDNA.

\section{EST annotation}

Following automatic removal of vector sequences, nucleotide sequences were assembled using LaserGene software (DNAStar, Madison, WI, USA) to determine redundancy among the EST sequences. All ESTs have been submitted to the GenBank dbEST database (accession numbers CN497248-CN498776). Consensus sequences were submitted in batch to the Blastx server to search GenBank non-redundant databases current as of September 2003. The top hit from the BLASTX search was deposited in a spreadsheet for further annotation and ease of data handling. Biological processes and molecular functions were assigned using GeneOntology (The Gene Ontology Consortium, 2001; http://www.geneontology.org/) based on annotation of the single 'best hit' match in BLASTX searches.

For the cadherin EST, the complete cDNA was sequenced by primer walking using primers derived from internal sequence. This was repeated until the ESTs had been sequenced three times on each strand of DNA. For the cathepsin ESTs, the nucleotide sequences were assembled in LaserGene as contigs and then the assemblies viewed manually to look for nucleotide differences likely to correspond to allelic variation or differences likely to correspond to proteins encoded by different loci. Comparative protein sequence analyses was carried out using the CLUSTALW analysis program with default parameters (DNAStar) and phylogenetic trees derived from the resulting alignments.

\section{Acknowledgements}

We thank Paul Wilkinson for DNA sequencing. The Biotechnology and Biology Research Council supported the research through the Underwood Fund provided to R.f.C. and B.D.S. This is journal series paper 14660, Nebraska Agricultural Research Division, and contribution no. 1191 of the Department of Entomology, University of Nebraska-Lincoln. 


\section{References}

Ball, H.J. and Weekman, G.T. (1963) Insecticide resistance in the western corn rootworm in Nebraska. J Econ Entomol 55: 439-441.

Brown, D.P., Wilkinson, H.S., Jongsma, M.A., and Gatehouse, J.A. (2004) Characterisation of cysteine proteinases responsible for digestive proteolysis in guts of larval western corn rootworm (Diabrotica virgifera) by expression in the yeast Pichia pastoris. Insect Biochem Mol Biol 34: 305-320.

Ellis, R.T., Stockhoff, B.A., Stamp, L., Schnepf, H.E., Schwab, G.E., Knuth, M., Russell, J., Cardineau, G.A., and Narva, K.E. (2002) Novel Bacillus thuringiensis binary insecticidal crystal proteins active on western corn rootworm, Diabrotica virgifera virgifera LeConte. Appl Environ Microbiol 68: 1137-1145.

Environmental Protection Agency (2003) Bacillus thuringiensis Cry3Bb1 Protein and the Genetic Material Necessary for its Production (Vector ZMIR13L) in Event MON863 Corn Fact Sheet. EPA Publication Number 730-F-03-01. Environmental Protection Agency, Washington, DC.

Ferré, J. and Van Rie, J. (2002) Biochemistry and genetics of insect resistance to Bacillus thuringiensis. Annu Rev Entomol 47: 501533.

Gaines, P.J., Brandt, K.S., Eisele, A.M., Wagner, W.P., Bozic, C.M., and Wisnewski, N. (2002) Analysis of expressed sequence tags from subtracted and unsubtracted Ctenocephalides felis hindgut and Malpighian tubule cDNA libraries. Insect Mol Biol 11: 299306.

Gatehouse, A.M.R., Butler, K.J., Fenton, K.A., and Gatehouse, J.A. (1985) Presence and partial characterisation of a major proteolytic enzyme in the larval gut of Callosobruchus maculatus. Entomol Exp App/ 39: 279-286.

Hill, C.A. and Guitierrez, J.A. (2000) Analysis of the expressed genome of the lone star tick, Amblyomma americanum (Acari: Ixodidae) using an expressed sequnece tag approach. Microbial Comparative Genomics 5: 89-101.

Hummel, H.E. (2003) Introduction of Diabrotica virgifera virgifera into the Old World and its consequences: a recently acquired invasive alien pest species on Zea mays from North America. Commun Agric Appl Biol Sci 68: 45-57.

Koiwa, H., Shade, R.E., Zhu-Salzman, K., D'Urzo, M.P., Murdock, L.L., Bressan, R.A., and Hasegawa, P.M. (2000) A plant defensive cystatin (soyasystatin) targets cathepsin L-like digestive cysteine proteinases (DvCALs) in the larval midgut of western corn rootworm (Diabrotica virgifera virgifera). FEBS Lett 471: 67-70.

Levine, E. and Oloumi-Sadeghi, H. (1991) Management of diabroticite rootworms in corn. Annu Rev Entomol 36: 229-255.

Levine, E., Spencer, S.A., Isard, Onstad, D.W., and Gray, M.E. (2002) Adaptation of the western corn rootworm, Diabrotica virgifera virgifera LeConte (Coleoptera: Chrysomelidae) to crop rotation: evolution of a new strain in response to a cultural management practice. Am Entomol 48: 94-107.

Lilley, C.J., Urwin, P.E., McPherson, M.J., and Atkinson, H.J. (1997) Characterization of intestinally active proteinases of cyst-nematodes. Parasitology 113: 415-424.
Liu, D., Burton, S., Glancy, T., Li, Z.S., Hampton, R., Meade, T., and Merlo, D.J. (2003) Insect resistance conferred by 283-kDa Photorhabdus luminescens protein TcdA in Arabidopsis thaliana. Nat Biotechnol 21: 1222-1228.

Loguercio, L.L., Barreto, M.L., Rocha, T.L., Santos, C.G., Teixeira, F.F., and Paiva, E. (2002) Combined analysis of supernatant-based feeding bioassays and PCR as a first-tier screening strategy for VIP-derived activities in Bacillus thuringiensis strains effective against tropical fall armyworm. J Appl Microbiol 93: 269-277.

Meinke, L.J., Siegfried, B.D., Wright, R.J., and Chandler, L.D. (1998) Adult susceptibility of Nebraska western corn rootworm (Coleoptera: Chrysomelidae) populations to selected insecticides. J Econ Entomol 91: 594-600.

Moellenbeck, D.J., Peters, M.L., Bing, J.W., Rouse, J.R., Higgins, L.S., Sims, L., Nevshemal, T., Marshall, L., Ellis, R.T., Bystrak, P.G., Lang, B.A., Stewart, J.L., Kouba, K., Sondag, V., Gustafson, V., Nour, K., Xu, D., Swenson, J., Zhang, J., Czapla, T., Schwab, G., Jayne, S., Stockhoff, B.A., Narva, K., Schnepf, H.E., Stelman, S.J., Poutre, C., Koziel, M., and Duck, N. (2001) Insecticidal proteins from Bacillus thuringiensis protect corn from corn rootworms. Nat Biotechnol 19: 668-672.

Morin, S., Biggs, R.W., Sisterson, M.S., Shriver, L., Ellers-Kirk, C., Higginson, D., Holley, D., Gahan, L.J., Heckel, D.G., Carriere, Y., Dennehy, T.J., Brown, J.K., and Tabashnik, B.E. (2003) Three cadherin alleles associated with resistance to Bacillus thuringiensis in pink bollworm. Proc Natl Acad Sci USA 100: 5004-5009.

Murdock, L.L., Shade, R.E., and Pomeroy, M.A. (1988) Effects of E64 , a cysteine proteinase inhibitor, on cowpea weevil growth, development, and fecundity. Eviron Entomol 17: 467-469.

O’Neal, M.E., Gray, M.E., Ratcliffe, S., and Steffey, K.L. (2001) Predicting western corn rootworm (Coleoptera: Chrysomelidae) larval injury to rotated corn with Pherocon AM traps in soybeans. J Econ Entomol 94: 98-105.

Pedra, J.J.F., Brandt, A., Westerman, R., Lobo, N., Li, H.-M., RomeroSeverson, J., Murdock, L.L., and Pittendrigh, B.R. (2003) Transcriptome analysis of the cowpea weevil bruchid: identification of putative proteinases and $\alpha$-amylases associated with food breakdown. Insect Molec Biol 12: 405-412.

The Gene Ontology Consortium (2001) Creating the gene ontology resource: design and implementation. Genome Res 11: 1425-1433.

Whitfield, C.W., Band, M.R., Bondaldo, M.F., Kumar, C.G., Liu, L., Pardinas, J.R., Robertson, H.M., Soares, M.B., and Robinson, G.E. (2002) Annotated expressed sequence tags and cDNA microarrays for studies of brain and behavior in the honey bee. Genome Res 12: 555-566.

Zhou, X., Scharf, M.E., Parimi, S., Meinke, L.J., Wright, R.J., and Chandlerr, L.D. (2002) Diagnostic assays based on esterase-mediated resistance mechanisms in western corn rootworms (Coleoptera: Chrysomelidae). J Econ Entomol 95: 1261-1266. 